\title{
Vitalii Semenovich Shneer (on His 80th Birthday)
}

DOI: $10.1134 /$ S0016793210040195

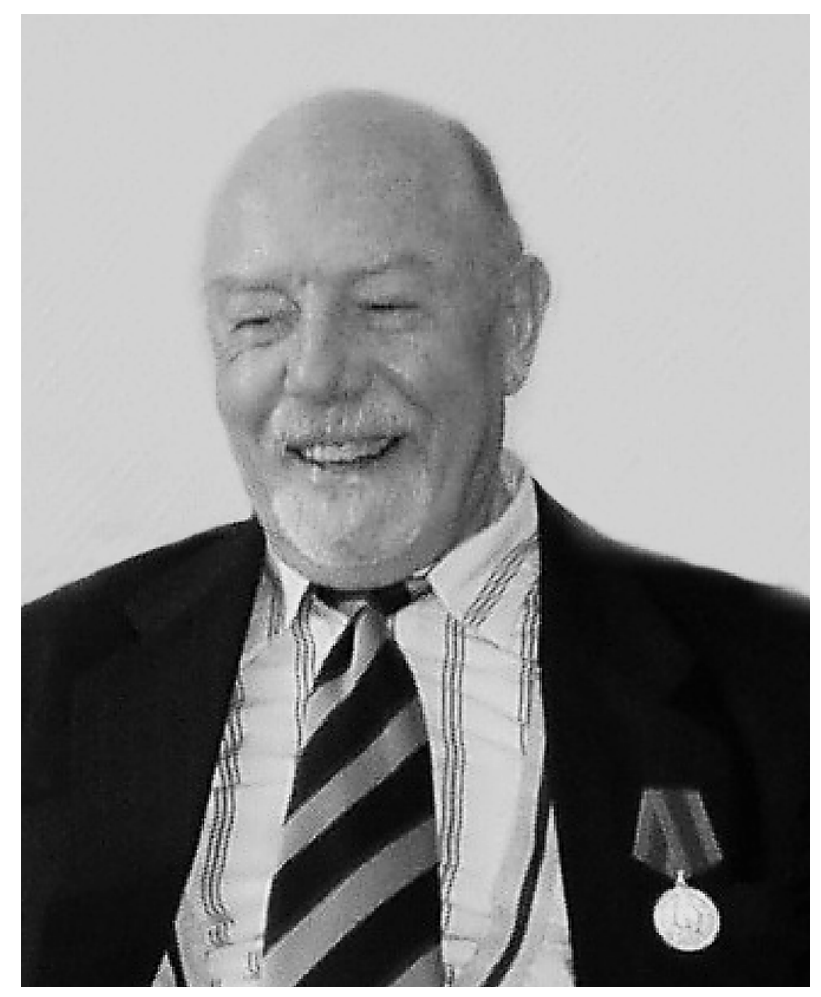

April 15, 2010 marked the 80th birthday of Vitalii Semenovich Shneer.

Shneer began his journey in science in 1954 at the Hydrographic Venture of the Ministry of the Navy with the study of Arctic seas. In 1957-1972, he worked at the Arctic and Antarctic Scientific-Research Institute of the Chief Directorate of the Geomagnetic Service, where he decisively took on the mantle of a scientist who dedicated his life to studying the Earth's electromagnetic field and as one of the pioneers of deep-sea electromagnetic research. Since 1972, Shneer worked at the Department of Maritime Electromagnetic Research of the Institute of Terrestrial Magnetism, Ionosphere, and Radio Wave Propagation, Russian Academy of Sciences, which in 1990 became an affiliate of the Institute of Solid Earth Physics, Russian Academy of Sciences (Institute of Geoelectromagnetic Research-Center for Geoelectromagnetic Research), where he successfully works to this day.

The present level of knowledge on electromagnetic processes in the ocean and the fact that Russia has, with a few other developed countries, entered the world's "maritime electromagnetic club," is inextricably linked to Shneer. An expert experimenter and, at the same time, possessing profound theoretical erudition, he posed a full set of maritime electromagnetic experiments, each one unique for its time. He personally took part in them in the harshest places-on drifting "North Pole" stations, in the Antarctic, and in the long run over the entire World Ocean, where on a large ship or a small sailboat, he was both researcher and sailor. For his activity in expeditions, Shneer was honored with the awards of "Honored Polar Explorer" and "Outstanding Worker of the USSR Hydrometeorological Service."

Shneer was an outstanding geophysicist, the author of more than 130 scientific works, and the creator of a number of inventions. His very important achievements are connected to the study of the Earth's alternating magnetic field, maritime magnetotelluric and magnetovariational sounding, and the study of the nature of the electromagnetic fields of currents. In particular, he proposed and was the first to implement a sounding method for the ocean floor in the field of a current, which was further developed in works by his students and colleagues. Under his high-principled guidance at the Institute of Terrestrial Magnetism, Ionosphere, and Radio Wave Propagation, he created a base of unique deep-sea equipment. Shneer's recent accomplishments include deep-sea monitoring of the vertical component of the electric field at Baikal, which has no other analog and gives continuously new results for basic geophysics.

Shneer belongs to the rare group of people who with no great desire accept administrative posts but whom subordinates follow with alacrity. Whatever he had to head up - an expedition, a laboratory, or an institute, he has always been able to inspire the collective with his sincere interest in scientific problems, even those far from his own subject area; with his erudition; his inviolable honesty; his civic-mindedness; and his rare charm. His leadership at the Institute of Geoelectromagnetic Research (1992-1999) is remembered as a golden age despite the overall difficulties shared by everyone.

His colleagues in geophysics and physics; polar explorers; oceanologists; and the editorial board of Geomagnetism and Aeronomy congratulate Vitalii Semenovich on his 80th jubilee and wish him further success in his beloved science. 